\title{
Multiple Endocrine Gland Apoplexy Post-snake Bite
}

\author{
Deepak Amalnath, Dipti Baskar \\ Department of General Medicine, JIPMER, Puducherry-605001, India.
}

\begin{abstract}
:
Background: Ophitoxemia is a major concern in tropical and subtropical countries resulting in multiple effects mostly in acute phase. Late sequelae such as renal failure are seen especially in vasculotoxic snake bites. There are very few case reports describing endocrine dysfunction as a late complication of vasculotoxic bites resulting in significant morbidity in such patients. Case Report: We report a patient who presented with pituitary and adrenal insufficiency after many months of snake bite. Pan-hypopituitarism and adrenal insufficiency were suspected and hormonal replacement was given which significantly improved the patient symptoms. Conclusion: High index of suspicion of multiglandular endocrine insufficiency should be suspected in post snake bite patients.
\end{abstract}

Key words: Adrenal Insufficiency, Hypopituitarism, Pituitary Diseases, Snake Bites, Renal Insufficiency.

\section{Introduction}

Vasculotoxic snakes in India belonging to Viperid family include Russell's viper, Saw scaled viper, Pit viper. Local envenomation and systemic haemostatic abnormalities leading to bleeding and shock occur due to various pro-coagulant and anticoagulant enzymes present in the venom. The resultant complications include acute kidney injury, disseminated intravascular coagulation, capillary leak syndrome, acute respiratory syndrome, etc. Erratic hemodynamic changes result in endocrine gland apoplexy resulting in insufficiency and hence should be considered in these patients. Chatterii et al. in their study of a profile of 86 hypopituitarism patients found that snake bite as an important etiological factor [1]. Involvement of multiple endocrine glands post-snake bite can occur during acute stage or after months or years [2]. High index of suspicion is required in such cases. We report a case where the patient presented with symptoms of insufficiency after many months of snake bite. Early hormonal replacement and supportive management is needed to improve the outcome in such cases.

\section{Case Report}

A 43 year old gentleman, farmer by occupation presented to us with easy fatigability and generalized myalgia for two months duration. This was accompanied by limb weakness which has progressed to the extent that he needed assistance

\section{Corresponding Author: Dr. Dipti Baskar}

Email: diptibaskar@gmail.com

Received: May 9, 2016 | Accepted: August 2, 2016 | Published Online: October 10, 2016

This is an Open Access article distributed under the terms of the Creative Commons Attribution License (creativecommons.org/licenses/by/3.0)

Conflict of interest: None declared | Source of funding: Nil | DOl: http://dx.doi.org/10.17659/01.2016.0115 
for walking long distances. During this period he also had two to three fainting episodes which got relieved on drinking fruit juices. He complained of decreased frequency of shaving the beard. Weight gain, constipation and impotence were also present. Patient had a past history of viper snake bite with acute kidney injury and hypotension for which he was treated in intensive care unit, recovered and was evaluated for endocrinopathy at that time but was found to be within normal limits and was discharged.

On examination patient was conscious, oriented and was in depressed mood. He was pale with decreased facial and axillary hair. Skin of the peripheries was coarse, cool and dry with increased pigmentation. Vitiligo of scrotal skin was seen. Haematological and biochemical tests were normal. Thyroid function tests revealed inappropriate normal thyoid stimulating hormone inspite of low free tetra and tri-iodothyronine, hence primary hypothyroidism was suspected and further hormonal assays were done which had the following pattern as given in Table 1. The hormone assay panel of the patient revealed that there is pan-hypopituitarism with primary adrenal insufficiency. MRI brain showed empty sella with intact posterior bright spot as in Fig.1. Patient was started on prednisolone along with thyroxine and fortnightly testosterone injection. Prompt improvement in general condition of the patient within weeks of starting replacement was seen. Steroid and thyroxine replacement was continued and regular hormone level assay was done. Patient recovered completely and was followed up regularly. Table 2 shows hormone profile at 3 months follow-up.

\section{Discussion}

Multiple endocrine gland insufficiencies, including hypopituitarism and adrenal insufficiency are commonly encountered entities in general practice. The prevalence and etiologies of these endocrine

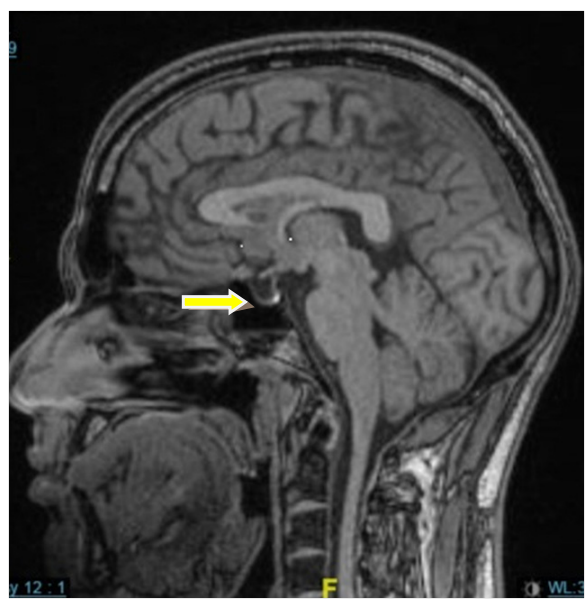

Fig.1: Plain MRI brain, sagittal view showing empty sella with intact posterior bright spot.

Table 1: Hormone assay panel - at admission.

\begin{tabular}{|c|c|c|}
\hline Hormone & Observed value & Reference value \\
\hline $\mathrm{FSH}^{*}$ & 1.92 & $5-20 \mathrm{IU} / \mathrm{L}$ \\
\hline $\mathrm{LH}^{\#}$ & 2.02 & $5-20 \mathrm{IU} / \mathrm{L}$ \\
\hline $\mathrm{TSH}^{\$}$ & 4.3 & $0.35-5.5 \mathrm{mlU} / \mathrm{mL}$ \\
\hline Prolactin & 2.37 & $2-18 \mathrm{ng} / \mathrm{mL}$ \\
\hline Testosterone & 75.63 & $241-827 \mathrm{ng} / \mathrm{dL}$ \\
\hline Parathormone & 23.6 & $10-65 \mathrm{pg} / \mathrm{mL}$ \\
\hline free $T 4^{\wedge}$ & 0.29 & $0.89-1.76 \mathrm{ng} / \mathrm{dL}$ \\
\hline free $T 3^{\epsilon}$ & 1.25 & $2.3-4.2 \mathrm{pg} / \mathrm{mL}$ \\
\hline Cortisol & 0.40 & $4.3-22.44 \mu \mathrm{g} / \mathrm{dL}$ \\
\hline IGF-17 & 29.1 & $101-267 \mathrm{ng} / \mathrm{mL}$ \\
\hline
\end{tabular}

"FSH: Follicle stimulating hormone, ${ }^{\mathrm{L}} \mathrm{LH}$ : Luteinizing hormone, ${ }^{\mathrm{T}} \mathrm{TSH}$ : Thyroid stimulating hormone, 'free T4: Free tetraiodothyronine, ${ }^{\epsilon}$ free T3: free tri-iodothyronine, ${ }^{\circledR}$ IGF-1: Insulin like growth hormone-1.

Table 2: Hormone assay panel - follow-up (3 months).

\begin{tabular}{|l|l|l|}
\hline Hormone & Patient value & Reference value \\
\hline $\mathrm{FSH}^{*}$ & 2.65 & $5-20 \mathrm{IU} / \mathrm{L}$ \\
\hline $\mathrm{LH}^{\#}$ & 3.69 & $5-20 \mathrm{IU} / \mathrm{L}$ \\
\hline $\mathrm{TSH}^{\$}$ & 5.0 & $0.35-5.5 \mathrm{mlU} / \mathrm{mL}$ \\
\hline Prolactin & 2.74 & $2-18 \mathrm{ng} / \mathrm{MI}$ \\
\hline Testosterone & 293 & $241-827 \mathrm{ng} / \mathrm{dL}$ \\
\hline Parathormone & 24.8 & $10-65 \mathrm{pg} / \mathrm{mL}$ \\
\hline free T4 & 1.09 & $0.89-1.76 \mathrm{ng} / \mathrm{dL}$ \\
\hline free T3 & 2.38 & $2.3-4.2 \mathrm{pg} / \mathrm{mL}$ \\
\hline Cortisol & 10.1 & $4.3-22.44 \mathrm{mcg} / \mathrm{dL}$ \\
\hline IGF- ${ }^{*}$ & 28.6 & $101-267 \mathrm{ng} / \mathrm{mL}$ \\
\hline
\end{tabular}

"FSH: Follicle stimulating hormone, ${ }^{*} \mathrm{LH}$ : Luteinizing hormone, ${ }^{\$} \mathrm{TSH}$ : Thyroid stimulating hormone, 'free T4: Free tetraiodothyronine, ${ }^{\epsilon}$ free T3: free tri-iodothyronine, ${ }^{*} I G F-1$ : Insulin like growth hormone-1. 
deficiencies are different between tropical countries and the West [1]. Among the numerous causes known, post-snake bite multiple endocrine gland insufficiency should be considered with high index of suspicion in tropical countries like India [2]. Vasculotoxic ophitoxemia is well known to occur following viperid snake bite [3]. The possible mechanisms include coagulation activating enzymes in viper venom, direct endothelial damage, abnormal platelet function, etc $[4,5]$. All these factors result in microthrombi formation associated with shock due to envenomation resulting in pituitary insufficiency, adrenal failure, etc. [6-9].

Our patient had insidious onset of vague symptoms like easy fatigability, giddiness, etc. On further detailed analysis of the patient, significant past history of snake bite with vasculotoxic complications was obtained. Further investigation showed pan-hypopituitarism associated with adrenal insufficiency by hormonal assay, a combination seen only in a few post-snake patients in the prior case reports. MRI brain showing empty sella turcica further supported our diagnosis. Following prompt hormonal replacement, significant recovery from symptoms was seen. Thus good clinical suspicion and timely intervention with steroids and other hormone replacement is very important.

\section{Conclusion}

Physicians while treating viperid snake bite patients should also have suspicion of polyendocrinopathy along with the usual vascular complications. Failure of one or more endocrine gland may occur not only in the acute phase but also after several months as seen in our case. Though pituitary is the commonest gland to be involved other endocrine glands especially adrenal gland should also be considered. Hence high degree of suspicion and hormone replacement is required at the earliest.

\section{References}

1. Chatteriee P, Mukhopadhyay P, Pandit K, Roychowdhury B, Sarkar D, Mukherjee S, et al. Profile of hypopituitarism in a tertiary care hospital of eastern India: Is quality of life different in patients with growth hormone deficiency. J Indian Med Assoc. 2008; 106:384385.

2. Dhanwal DK, Das AK. Hypopituitarism following snake bite. J Assoc Physicians India. 1998;46:322.

3. Kalra S, Dhanwal D, Vaman K. Hypopituitarism in the tropics. Indian Journal of Endocrinology and Metabolism. 2011;15:151-153.

4. Antonypillai CN, Wass JA, Warrell DA, Rajaratnam HN. Hypopituitarism following envenoming by Russell's vipers (Daboiasiamensis and D. russelii) resembling Sheehan's syndrome: First case report from Sri Lanka, a review of the literature and recommendations for endocrine management. QJM. 2011 ;104:97-108.

5. Than-Than, Fancis N, Tin Nu, Myint Lwin, TunPe, Soe-soe, et al. Contribution of focal hemmorage and microvascular fibrin deposition to fatal envenoming by Russell viper in Burma. Acta Trop. 1989;46:23-38.

6. Uberoi HS, Achuthan AC, Kasthuri AS, Kolhe VS, Rao KR, Dugal JS. Hypopituitarism following snake bite. J Assoc Physicians India. $1991 ; 39(7): 579-580$.

7. Devaraj T. Bleeding manifestations in snake bite. Southeast Asian J Trop Med Public Health. 1979;10(2):255-257.

8. Denson KWE. Coagulant and anti-coagulant action of snake venom. Toxicon. 1969;7:5.

9. Braud S, Bon C, Wisner A. Snake venom proteins acting on hemostasis. Biochimie. 2000;82:851859. 